\title{
Leaders' Emotional Labor Strategies and Wellbeing: Does Perceived Organizational Justice Mediates the Relationship?
}

\author{
Qasim Ali Nisar ${ }^{1}$, Noraini Othman ${ }^{2}$, Bidayatul Akmal Mustafa Kamil ${ }^{3}$ \\ ${ }^{1}$ Ph.D. Candidate, School of Business Management, Universiti Utara Malaysia, Lecturer, \\ Superior University Lahore, Pakistan \\ ${ }^{2}$ Associate Professor, School of Business Management, Universiti Utara Malaysia \\ ${ }^{3}$ Senior Lecturer, School of Business Management, Universiti Utara Malaysia \\ Email:
}

\begin{abstract}
As emotions play a crucial role in organizations, many researchers have turned their attention to examining emotions in organizational behavior studies to gain a more in-depth understanding of human behaviors within organizations. Leaders' emotions are deemed important as key elements of effective leadership. Leaders attempt to manage their emotions when interacting with their followers, and these emotions ultimately influence their wellbeing and attitudes. Perceived organizational justice is also proposed as an important factor that might intervene this relationship. Hence, this paper proposed a theoretical framework for studying the relationship between leaders' emotional labor strategies and wellbeing, in which perceived organizational justice is the mediating factor.
\end{abstract}

Keywords: Emotions, Emotional Labor, Leaders' Wellbeing, Emotional Exhaustion, Organizational Commitment, Perceived Organizational Justice

\section{Introduction}

Emotions are considered as key factors in human resource research. As such, many researchers have paid great attention to emotions in their studies (e.g. Callahan, 2000; Kunnanatt, 2004; McEnrue \& Groves, 2006). Organizations identified emotions in organizational outcomes as a cornerstone to survive in competitive work boundaries. Recent studies (Ahmad-Mughal, Nisar, Othman, \& Kamil, 2017; Butt, Nisar, Nadeem, \& Baig, 2017) have realized the importance of integration between organizational behaviors and emotions to gain effective outcomes and modern theories of emotions. Therefore, researchers have turned their attention to examining emotions in organizational behavior studies to gain a more indepth understanding of human behaviors within organizations. Furthermore, studies also proposed that employees' emotional display has a positive association with employees' 
performance, satisfaction, psychological well-being and overall organizational outcomes (Pugh, 2001; Tsai, 2001; Tsai \& Huang, 2002). These findings further revealed that emotional display develops a positive relationship with clients which foster a competitive advantage. For this reason, organizations need to ensure their employees to display the required emotions and attitudes when interacting with others (Grandey, 2000).

Tang, Gu, and Cui (2017) recommended that emotion is the most common challenge in organizational behavior and leadership, depending on the ability of leaders to manage and use their own emotions in employee emotion management. By considering this point of view, emotional labor has been introduced as a new work demand. Emotional labor is considered a crucial concept in management studies due to its effective relationship with employees' outcomes such as employees' retention, burnout and their job satisfaction (Brotheridge \& Lee, 2003; Rubin, Tardino, Daus, \& Munz, 2005), which in turn, affect customers' satisfaction and overall organizational performance (Cordes \& Dougherty, 1993; Gelade \& Young, 2005; Volker et al., 2010; Williams \& Skinner, 2003).

In the perspective of leadership, emotional labor strategies play a vital role in leadership effectiveness. Leaders' emotions that influence their behaviors and followers' outcomes might leads to effective leadership (Humphrey, Ashforth, \& Diefendorff, 2015; Humphrey, Burch, \& Adams, 2016; Miao, Humphrey, \& Qian, 2016; Wang, 2011). Previously, few studies identified and introduced leaders' emotional labor concept in leadership (Brotheridge, Lee, Humphrey, Pollack, \& Hawver, 2008; Gardner, Fischer, \& Hunt, 2009; Rathi, Bhatnagar, \& Mishra, 2013; Torland, 2013; Wang, 2011). According to Ottenbacher and Harrington (2010), there is a need for exploring the crucial role of emotional labor associated with leadership due to the competitive and dynamic environment. Organizations paid great attention towards their leadership effectiveness and emotional labor strategies which considered to be key elements associated with effective leadership (Brotheridge, Lee, Boss, \& Sims Jr, 2008; Humphrey, 2008, 2012). Meanwhile, Bono and Vey (2005b) argued that emotional labor is considered an integral part of organizational productivity and profitability in businesses. Therefore, the purpose of this study is to highlight the importance of emotions at the workplace and to examine the role of leaders' emotional labor strategies towards their wellbeing. Moreover, this study also proposed the mediating role of perceived organizational justice between leaders' emotional labor strategies and wellbeing (organizational commitment and emotional exhaustion). 


\section{Literature Review}

Leaders' attitudes and well-being leads to effective leadership. Previous studies almost ignored to integrate leaders' emotions with their attitudes and wellbeing. Nevertheless, several studies found that leaders' emotions play a significant role to influence their wellbeing (e.g., Humphrey et al., 2015; Humphrey et al., 2016; Torland, 2013; Wang, 2011). Given the importance of emotional labor, it is highly valuable to explore and investigate how leaders' emotional labor strategies related to leaders' wellbeing (organizational commitment and emotional exhaustion). Besides that, the role of perceived organizational justice as a mediator will be also examined.

\section{A. Leaders' Wellbeing}

In this study, the wellbeing of leaders comprised of two constructs, namely, organizational commitment and emotional exhaustion.

\section{Organizational Commitment}

Organizational commitment is conceptualized as "strength of an individual's identification with and involvement in an organization" (Porter, Steers, Mowday, \& Boulian, 1974). Highly committed employees put great efforts on behalf of their organization to achieve organizational values and goals (Steers, 1977). A study conducted by Salancik (1977) defined organizational commitment as "a state of being in which an individual becomes bound by his actions and through these actions to beliefs that sustain the activities of his own involvement". While another study refers organizational commitment as "the relative strength of an individual's identification with and involvement in a particular organization" (Mowday, Steers, \& Porter, 1979). They further described it as the degree of individuals' readiness and willingness to put his efforts for organizational achievement. Besides that, O'Reilly and Chatman (1986), in their study conceptualized organizational commitment as "the psychological attachment felt by the person for the organization; it will reflect the degree to which the individual internalizes or adopts characteristics or perspectives of the organization". Meanwhile, Mathieu and Zajac (1990) refer organizational commitment as "a bond or linking of the individual to the organization".

Furthermore, Allen and Meyer (1990) defined it as "psychological state that binds the employees to the organization" and introduced a model for commitment which contains three components such as normative commitment, affective commitment, and continuance commitment. Normative commitment refers to individuals' feelings of responsibility and obligation to attach with the organization, and this type of commitment is determined by 
employees' experiences, values, attitudes and socio-cultural background before joining the organization (Newman, Thanacoody, \& Hui, 2011). Similarly, in affective commitment, employees have emotional attachment and identification with the organization and enjoy their involvement and membership in their organization. Continuance commitment is defined as perceptions regarding the cost when they have to go away and leave the organization (Allen \& Meyer, 1990). In 1990s, organizational commitment was the major focus of research studies and great attention has been paid to theories development for organizational commitment (Meyer, Stanley, Herscovitch, \& Topolnytsky, 2002).

\section{Emotional Exhaustion}

Emotional exhaustion is considered the crucial element of burnout (Maslach, 1982). Jackson, Turner, and Brief (1987) defined emotional exhaustion as a stress-related reaction and state of exhausted energy due to excessive and unnecessary emotional and psychological demands. According to Wright and Cropanzano (1998), emotional exhaustion it is manifested by feelings of emotionally and psychologically drained. Similarly, it described the feelings of being emotionally exhausted by work (Frijda, 1994; Maslach \& Jackson, 1981). Shirom (2005) argued that emotional exhaustion is a core element of burnout and refers to the employees' feelings of exhaustion and tiredness and being emotionally overloaded and overextended while interacting with others- Meanwhile, Maslach, Schaufeli, and Leiter (2001) refer emotional exhaustion as "stress-related exhaustion of the emotional and physical power of the individual". It is the stage where individual's energy depleted by excessive demands regarding emotions display while interacting with others (Khan, Imran, \& Nisar, 2016; Saxton, Phillips, \& Blakeney, 1991).

\section{B. Leaders' Emotional Labor Strategies}

Hochschild (1983) was the first researcher who proposed that deep acting and surface acting as two major dimensions of emotional labor. Study results also identified passive deep acting and active deep acting as dimensions of emotional labor. In passive deep acting, employees' emotions managed automatically while in active deep acting employees express their emotions consciously according to situations. Moreover, Humphrey was the first researcher who introduced this concept in leadership literature and proposed that leaders adopt emotional labor strategies when they express their emotions to influence followers' motivation and moods. Humphrey and his colleagues defined emotional labor as a process which leaders adopt to manage their emotions to influence their subordinates. By referencing Hochschild's theory, they also defined surface acting as a process in which leaders manipulate 
their outer emotions but in reality, they don't feel that emotions. Similarly, deep acting also defined as a process in which leaders put efforts to experience the real emotions they display (Humphrey at al., 2008). Surface acting and deep acting both deemed to be compulsory and effective strategies that leaders adopt when they didn't display suitable emotions impulsively (Totterdell \& Holman, 2003; Grandey, 2003). The concept of leaders' emotional labor still treated theoretically. Literature highlighted that role of emotional labor in leadership almost ignored. During the review, few studies found that identified and introduced leaders' emotional labor concept in leadership literature (Humphrey et al., 2008; Gardner et al., 2009; Wang, 2011; Rathi et al., 2013; Torland, 2013).

\section{Organizational Justice}

Organizational justice can be defined as individuals' sense of fairness within the organization (Di Fabio \& Palazzeschi, 2012). Byrne and Cropanzano (2001) refer organizational justice as "at its most general level, organizational justice is an area of psychological inquiry that focuses on perceptions of fairness in the workplace". Similarly, organizational justice is all about the individuals' perceptions regarding fairness and equality in outcomes, processes for that outcome and the way they are treated by others (Cropanzano, Rupp \& Byrne, 2003).

According to Bies and Moag (1986), organizational justice consists of three dimensions such as interactional justice, procedural justice, and distributive justice. Procedural justice referred as "perceived fairness of the procedures used to determine the outcomes that an employee receives" (Greenberg, 1990). Distributive justice is defined as "perceived fairness of the distributive outcomes that an employee receives from an organization" (Folger \& Cropanzano, 1998). It reflects the employees' elucidation regarding the appropriateness and fairness of employment outcomes (Yucel, 2013). Organizational justice was originated from equity theory developed by Adams (1965). According to this theory, individual makes perception on their outcomes and matches their outcomes with their own as well as others' efforts and contribution. Gurbus and Mert (2009) argued that employees compare their outcomes with others and in comparison, results, they believe that they are treated unfairly or fairly Furthermore, Lambert (2003) stated that organizational justice is also considered as a predictor of organizational effectiveness.

\section{Leaders' Emotional Labor Strategies and Wellbeing}

Recent studies integrated the-leaders' emotional labor strategies with their wellbeing and directed that there is in need to further examine the role of leaders' emotions in leadership 
studies (Humphrey et al., 2015; Humphrey et al., 2016). In this study, leaders' wellbeing is conceptualized of organizational commitment and emotional exhaustion.

\section{E. Emotional Labor Strategies and Organizational Commitment}

Cho, Rutherford, and Park (2013) examined the effect of emotional labor on retail environment among 221 salesmen in South Korea. They further investigated the effect of emotional labor and emotional exhaustion on employees' organizational commitment. Results proved that emotional labor as a significant predictor of affective organizational commitment. Moreover, affective events theory (cite the scholar) also supports this logical relationship between emotional labor and organizational commitment. According to this theory, emotional labor significantly affects individuals' attitudes and behaviors. Furthermore, another study examined the influence of emotional labor on employees' commitment and their performance. Data were collected from 136 nurses working in community hospitals. Results of this study also revealed that surface acting has a significant and negative effect on employees' organizational commitment. While the deep acting is positively and significantly related to organizational commitment (Ghalandari, Jogh, Imani, \& Nia, 2012).

Similarly, Bozionelos and Kiamou (2008) also studied the relationship between emotional labor strategies and organizational commitment and highlighted that both dimensions of emotional labor (surface acting, deep acting) has a negative association with organizational commitment. Besides this, another study elucidated that employees with the frequent use of emotional labor with balanced thinking feel strong organizational commitment (Groves \& Vance, 2007). One of the previous studies also examined the relationship between emotional labor and organizational commitment among nursing staff. Results revealed that surface acting positively influence employees' commitment (Yang \& Chang, 2008). In addition, a study conducted on among childcare employees and elaborated the same findings regarding the negative correlation between surface acting and organizational commitment (Seery \& Corrigall, 2009). Furthermore, Rathi et al. (2013) conducted a study to examine the crucial role of emotional labor for employees' organizational commitment in the hospitality sector, which comprised of 204 frontline hotel employees. Findings showed that both dimensions of emotional labor have a significant relationship with employees' commitment. Meanwhile, Humphrey et al. (2015) explored the bright side of emotional labor and their results illuminated that deep acting is not harmful to individuals' wellbeing. Their study further revealed that deep acting was significantly and positively related to performance, 
satisfaction and organizational commitment. In contrast, surface acting was found to has a negative relationship with these constructs (Humphrey et al., 2015).

Even though there are studies on the relationship between emotional labor strategies and organizational commitment, however, limited research is available in the context of leadership. Thus, more study is needed to provide more understanding of this relationship.

\section{F. Emotional Labor Strategies and Emotional Exhaustion}

Numerous studies examined the effect of emotional labor strategies on emotional exhaustion (e.g., Chau, Dahling, Levy, \& Diefendorff, 2009; Hülsheger \& Schewe, 2011; Ibanez-Rafuse, 2010; Lee \& Chelladurai, 2016; Martínez-Iñigo, Totterdell, Alcover, \& Holman, 2007; Raman, Sambasivan, \& Kumar, 2016; Rathi et al., 2013; Sohn, Lee, \& Yoon, 2016; Wang, 2011). A meta-analytic study by Kammeyer-Mueller et al. (2013) reviewed 116 primary studies and found that surface acting is negatively and significantly related to individuals' outcomes such as exhaustion and stress. Different meta-analyses proved that surface acting has a significant association with stress and it also harmful for wellbeing (Bono \& Vey, 2005a, 2005b; Hayyat, Nisar, Imran, \& Ikram, 2017; Hülsheger \& Schewe, 2011; Kammeyer-Mueller et al., 2013; Wang, Seibert, \& Boles, 2011).

In addition, a study by Kammeyer-Mueller et al. (2013) further revealed that deep acting was positively related to work-related outcomes. Meanwhile, a recent study by Nisar, Imran, Othman, Kamil, and Marchalina (2017) revealed that deep acting was negatively and significantly associated with emotional exhaustion. Previous studies argued that individuals who adopt deep acting and modify their emotions according to the required situation have less emotional exhaustion level than others (Johnson \& Spector, 2007; Lee \& Chelladurai, 2016; Philipp \& Schüpbach, 2010; Sohn et al., 2016; Wang, 2011). Although there are studies on the relationship between emotional labor and emotional exhaustion, however, there is still lack of research in examining the role of emotional labor strategies with regards to leadership effectiveness.

\section{G. Mediating Role of Perceived Organizational Justice}

Recent studies also highlighted the crucial role of perceived organizational justice in emotions management studies. Leaders manage their emotions more effectively if they perceive to be treated fairly while performing required emotions (Martínez-Íñigo \& Totterdell, 2016). Furthermore, previous empirical studies showed basic reason behind the individuals' psychological disturbance is negative and unfair perceptions regarding justice (Greenberg, 2006). Justice and perceived fairness play a significant role and explain the 
relationship between emotions regulations and individuals' behaviours (Martínez-Íñigo \& Totterdell, 2016). Furthermore, previous studies completely ignored the mediating role of justice in emotions regulation and wellbeing relationship as Martínez-Íñigo and Totterdell (2016) claimed in their study that previously no study investigated the mediating role of distributive justice between the relationship of emotions regulation and individuals' wellbeing. Moreover, the role of perceived organizational justice with respect to emotions regulation is not acknowledged and encouraged by organizations (Glomb, KammeyerMueller, \& Rotundo, 2004; Grandey, Chi, \& Diamond, 2013). Meanwhile, Martínez-Íñigo and Totterdell (2016) introduced distributive justice and examined the mediating role of distributive justice between the association of emotional regulation strategies and emotional exhaustion. This study highlighted that procedural and interactional justice may be included as a mediator between emotional regulations and emotional exhaustion as previously dimension of justice were ignored in emotions related studies. In addition, organizational justice can be added in further studies as a mediator in emotional labour and wellbeing studies (Martínez-Íñigo \& Totterdell, 2016), therefore this study fills this gap by introducing organizational justice as a mediator between the relationship of leaders' emotional labour and outcomes.

\section{H. Gaps in Literature}

Wang (2011) claimed that its need to examine the leaders' attitudes and wellbeing in further studies. In addition, emotional exhaustion is deemed as more dominance to measure the leaders' attitudes as some of the recent studies also used it to measure the leaders' behaviors (Wang, 2011). Moreover, the emotional regulation theory also supports that leaders experience emotional exhaustion while interacting their followers, as sometimes they have to express unwanted emotions which leads to increase exhaustion level (Grandey, 2000; Gross, 1998). Therefore, this study is going to measure the leaders' emotional exhaustion while measuring their attitudes and wellbeing because recent studies identified that there is need to examine the negative consequences of emotions management (Wilding, Chae, \& Jang, 2015). Furthermore, this study also included an organizational commitment in leaders' attitudes as the bright side of leaders' behaviors with respect to emotions is almost ignored in previous studies (Li \& Liang, 2016). Similarly, one of the recent studies examined the impact of emotional labor on an effective commitment for salesman working in South Korea. This study identified that further studies should integrate emotional labor with overall organizational commitment (Cho et al., 2013). Moreover, another study also considered organizational 
commitment and employees' performance as an important dimension to measure the individuals' attitudes and behaviors (Harrison, Newman, \& Roth, 2006).

Beside this, a recent study also highlighted the crucial role of perceived organizational justice in emotions management studies. Leaders manage their emotions more effectively if they perceive to be treated fairly while performing required emotions (MartínezÍñigo \& Totterdell, 2016). Furthermore, previous empirical studies showed basic reason behind the individuals' psychological disturbance is negative and unfair perceptions regarding justice (Greenberg, 2006). Justice and perceived fairness play a significant role and explain the relationship between emotions regulations and individuals' behaviours (Martínez-Íñigo \& Totterdell, 2016). Furthermore, previous studies completely ignored the mediating role of justice in emotions regulation and wellbeing relationship as Martínez-Íñigo and Totterdell (2016) claimed in their study that previously no study investigated the mediating role of distributive justice between the relationship of emotions regulation and individuals' wellbeing. Moreover, the role of perceived organizational justice with respect to emotions regulation is not acknowledged and encouraged by organizations (Glomb, KammeyerMueller, \& Rotundo, 2004; Grandey, Chi, \& Diamond, 2013). Meanwhile, Martínez-Íñigo and Totterdell (2016) introduced distributive justice and examined the mediating role of distributive justice between the association of emotional regulation strategies and emotional exhaustion. This study highlighted that procedural and interactional justice may be included as a mediator between emotional regulations and emotional exhaustion as previously dimension of justice were ignored in emotions related studies. In addition, organizational justice can be added in further studies as a mediator in emotional labour and wellbeing studies (Martínez-Íñigo \& Totterdell, 2016), therefore this study fills this gap by introducing organizational justice as a mediator between the relationship of leaders' emotional labour and outcomes. This study is based on of Social exchange theory (Homans \& Merton, 1961) and emotions regulation model (Gross, 1998) as the given framework is based on these two underpinning theories.

\section{Propositions}

From the preceding discussion, the following propositions are put forth:

Proposition 1: Leaders' surface acting will have a significant influence on leaders' commitment.

Proposition 2: Leaders' deep acting will have a significance influence on leaders' commitment. 
Pakistan Journal of Humanities and Social Sciences, 6(1), 2018

Proposition 3: Leaders' surface acting will have a significance influence on leaders' emotional exhaustion.

Proposition 4: Leaders' deep acting will have a significance influence on leaders' emotional exhaustion.

Proposition 5: Perceived organizational justice will mediate the relationship between leaders' emotional labor and leaders' commitment.

Proposition 6: Perceived organizational justice will mediate the relationship between leaders' emotional labor and leaders' emotional exhaustion.

\section{Research Framework}

The following framework is developed on the basis of social exchange theory (Homans \& Merton, 1961), emotions regulation model (Gross, 1998), theoretical gaps and previous literature. Future studies may empirically test this model. It is proposed that leaders' emotional labor strategies (surface acting \& deep acting) may have a significant role towards their well-being (organizational commitment and emotional exhaustion). Moreover, organizational justice is perceived to mediate the relationship between leaders' emotional labor strategies and their well-being.

Figure 1

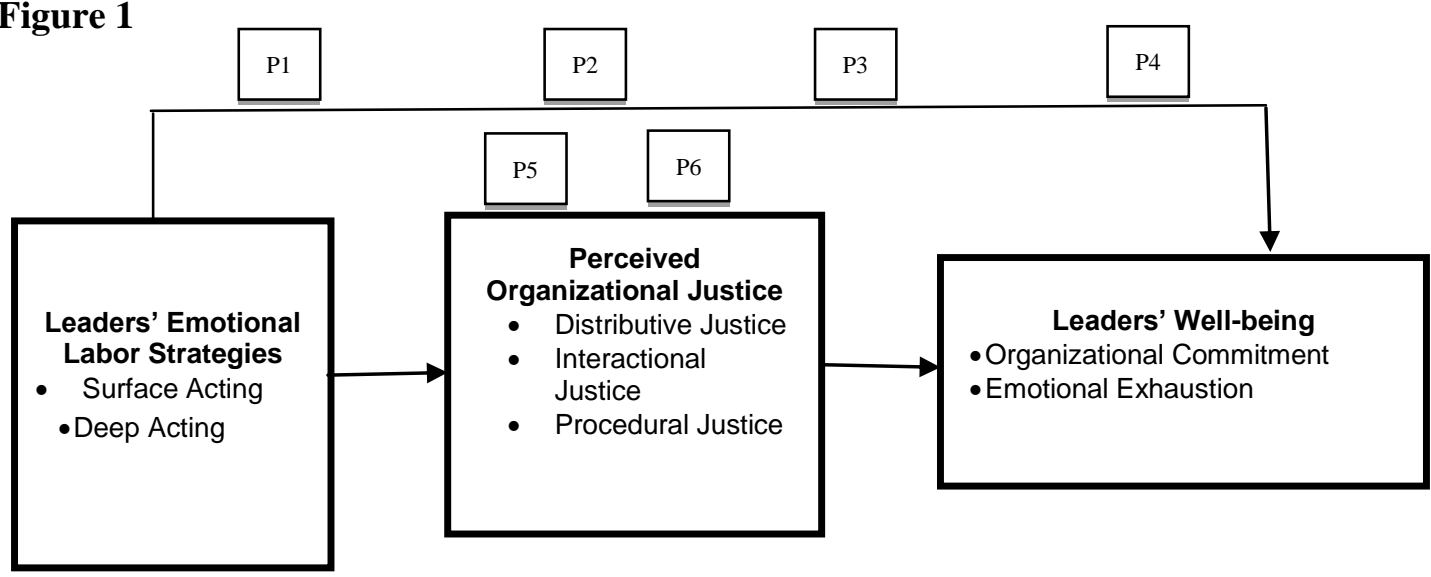

\section{Discussion and Conclusion}

Emotions are considered valuable for human experiences that regulate the human actions and thoughts. In past, emotions in workplace supposed irrelevant and unimportant therefore not perceived as workplace essential phenomenon (Grandey, 2000). However, in the last few years, organizational management and researchers realized the importance of emotions and its benefits at the workplace. Emotions in the workplace become more demanding due to competitive pressure in the services sector. Leaders' positive emotions directly related to the evaluation of organizations' services quality (Pugh, 2001). Moreover, 
leaders with effective use of an appropriate variety of emotional labor strategies have their followers with high performance and positive job attitudes. When leaders adopt emotional labor strategies, it may influence their well-being and attitudes.

Therefore, the purpose of this study was to identify the key role of leaders' emotions management for their well-being. This study proposed that leaders' emotional labor strategies may have a significant contribution towards their well-being. On the basis of underpinning theories and literature review, this study identified that leaders' emotional labor strategies play a significant role to shape the leaders' behaviors and attitudes. Furthermore, literature supported this argument that leaders' emotional labor strategies (surface acting \& deep acting) has a significant relationship with leaders' well-being (organizational commitment and emotional exhaustion). On the basis of extensive literature review, this study proposed that surface acting may have a positive association with emotional exhaustion and negatively related to organizational commitment. Meanwhile, deep acting also may be negatively related to leaders' emotional exhaustion and positively related to their organizational commitment. Moreover, the study also highlighted the mediating role of perceived organizational justice between leaders' emotional labor strategies and well-being (organizational commitment and emotional exhaustion). Thus, this study proposed that perceived organizational justice is an important factor that may intervene this relationship.

This study proposed a theoretical framework that needs to empirically tested in future studies. Further studies may test this framework empirically to gain insight understanding regarding the association of these understudy constructs.

\section{Limitations and Future Directions}

This study has several limitations that need to be addressed in future research. This study is conceptual in nature and did not empirically test the understudy constructs. It proposed a research framework on the basis of theories and previous literature. Therefore, future studies may want to test this proposed framework empirically to practically examine the role of leaders' emotional labor strategies towards their well-being by concentrating the mediating role of perceived organizational justice. Moreover, this study only focused on leaders' well-being and ignored to the followers' perspectives. Recent studies signified that leaders' emotional labor strategies play a great role to shape their followers' behaviors. As such, future studies might want to focus on followers' behaviors. 
Pakistan Journal of Humanities and Social Sciences, 6(1), 2018

\section{References}

Adams, J. S. (1965). Inequity in social exchange. Advances in experimental social psychology, 2, 267-299.

Ahmad-Mughal, S., Nisar, Q. A., Othman, N., \& Kamil, B. A. M. (2017). Do Emotional Intelligence \& Organizational Politics influence the Employee Work Behaviors and attitudes? Mediating Role of Political Skill. Jurnal Pengurusan, 51, 261-271.

Allen, N. J., \& Meyer, J. P. (1990). The measurement and antecedents of affective, continuance and normative commitment to the organization. Journal of occupational psychology, 63(1), 1-18.

Bies, R. J., \& Moag, J. S. (1986). Interactional justice: Communication criteria of fairness. Research on negotiation in organizations, $1(1), 43-55$.

Bono, J. E., \& Vey, M. A. (2005a). Toward understanding emotional management at work: A quantitative review of emotional labor research.

Bono, J. E., \& Vey, M. A. (2005b). Toward understanding emotional management at work: A quantitative review of emotional labor research Emotions in organizational behavior (pp. 224-244): Psychology Press.

Bozionelos, N., \& Kiamou, K. (2008). Emotion work in the Hellenic frontline services environment: How it relates to emotional exhaustion and work attitudes. The International Journal of Human Resource Management, 19(6), 1108-1130.

Brotheridge, \& Grandey, A. A. (2002). Emotional labor and burnout: Comparing two perspectives of "people work". Journal of vocational behavior, 60(1), 17-39.

Brotheridge, \& Lee, R. T. (2003). Development and validation of the emotional labour scale. Journal of Occupational and Organizational Psychology, 76(3), 365-379.

Brotheridge, C. M., Lee, R. T., Boss, A. D., \& Sims Jr, H. P. (2008). Everyone fails! Using emotion regulation and self-leadership for recovery. Journal of managerial psychology, 23(2), 135-150.

Brotheridge, C. M., Lee, R. T., Humphrey, R. H., Pollack, J. M., \& Hawver, T. (2008). Leading with emotional labor. Journal of managerial psychology, 23(2), 151-168.

Butt, S. S., Nisar, Q. A., Nadeem, S., \& Baig, F. (2017). Longitudinal study to examine the influence of emotional intelligence on organizational citizenship behavior: Mediating role of political skills. WALIA Journal, 33(1), 54-63.

Callahan, J. L. (2000). Emotion management and organizational functions: A case study of patterns in a not-for-profit organization. Human Resource Development Quarterly, 11(3), 245.

Chau, S. L., Dahling, J. J., Levy, P. E., \& Diefendorff, J. M. (2009). A predictive study of emotional labor and turnover. Journal of Organizational Behavior, 30(8), 1151-1163.

Cho, Y.-N., Rutherford, B. N., \& Park, J. (2013). The impact of emotional labor in a retail environment. Journal of Business Research, 66(5), 670-677.

Cordes, C. L., \& Dougherty, T. W. (1993). A review and an integration of research on job burnout. Academy of Management Review, 18(4), 621-656. 
Di Fabio, A., \& Palazzeschi, L. (2012). Organizational justice: Personality traits or emotional intelligence? An empirical study in an Italian hospital context. Journal of Employment Counseling, 49(1), 31-42.

Folger, R. G., \& Cropanzano, R. (1998). Organizational justice and human resource management (Vol. 7): sage publications.

Frijda, N. H. (1994). Emotions are functional, most of the time.

Gardner, W. L., Fischer, D., \& Hunt, J. G. J. (2009). Emotional labor and leadership: A threat to authenticity? The Leadership Quarterly, 20(3), 466-482.

Gelade, G. A., \& Young, S. (2005). Test of a service profit chain model in the retail banking sector. Journal of Occupational and Organizational Psychology, 78(1), 1-22.

Ghalandari, K., Jogh, M. G. G., Imani, M., \& Nia, L. B. (2012). The effect of emotional labor strategies on employees job performance and organizational commitment in hospital sector: moderating role of emotional intelligence in Iran. World Applied Sciences Journal, 17(3), 319-326.

Glomb, T. M., Kammeyer-Mueller, J. D., \& Rotundo, M. (2004). Emotional labor demands and compensating wage differentials. Journal of Applied Psychology, 89(4), 700.

Grandey, A. A. (2000). Emotional regulation in the workplace: A new way to conceptualize emotional labor. Journal of occupational health psychology, 5(1), 95.

Grandey, A. A. (2003). When "the show must go on": Surface acting and deep acting as determinants of emotional exhaustion and peer-rated service delivery. Academy of Management Journal, 46, 86-96.

Grandey, A. A., Chi, N. W., \& Diamond, J. A. (2013). Show me the money! Do financial rewards for performance enhance or undermine the satisfaction from emotional labor? Personnel Psychology, 66(3), 569-612.

Greenberg, J. (1990). Organizational justice: Yesterday, today, and tomorrow. Journal of management, 16(2), 399-432.

Greenberg, J. (2006). Losing sleep over organizational injustice: attenuating insomniac reactions to underpayment inequity with supervisory training in interactional justice. Journal of Applied Psychology, 91(1), 58.

Gross, J. J. (1998). Antecedent-and response-focused emotion regulation: divergent consequences for experience, expression, and physiology. Journal of personality and social psychology, 74(1), 224.

Groves, K. S., \& Vance, C. M. (2007). EXAMINING THINKING STYLE, EQ, AND ORGANIZATIONAL COMMITMENT IN THE CONTEXT OF EMOTIONAL LABOR. Paper presented at the Academy of Management Proceedings.

Harrison, D. A., Newman, D. A., \& Roth, P. L. (2006). How important are job attitudes? Meta-analytic comparisons of integrative behavioral outcomes and time sequences. Academy of management Journal, 49(2), 305-325.

Hayyat, U., Nisar, Q. A., Imran, M., \& Ikram, M. (2017). Consequences of Emotional Labor in Health Sector of Pakistan. International Journal For Research In Business, Management And Accounting, 3(6), 64-79.

Hochschild, A. R. (1983). The managed heart. Berkeley: CA: University of California Press. 
Pakistan Journal of Humanities and Social Sciences, 6(1), 2018

Homans, G. C., \& Merton, R. K. (1961). Social Behavior: Its Elementary Forms: Under the General Editorship of Robert K. Merton: Harcourt, Brace \& World.

Hülsheger, U. R., \& Schewe, A. F. (2011). On the costs and benefits of emotional labor: a meta-analysis of three decades of research. Journal of occupational health psychology, 16(3), 361.

Humphrey, R. H. (2008). The right way to lead with emotional labor. Affect and emotion: New directions in management theory and research, 1-17.

Humphrey, R. H., Pollack, J. M., \& Hawver, T. (2008). Leading with emotional labor. Journal of Managerial Psychology, 23, 151-168.

Humphrey, R. H. (2012). How do leaders use emotional labor? Journal of Organizational Behavior, 33(5), 740-744.

Humphrey, R. H., Ashforth, B. E., \& Diefendorff, J. M. (2015). The bright side of emotional labor. Journal of Organizational Behavior, 36(6), 749-769.

Humphrey, R. H., Burch, G. F., \& Adams, L. L. (2016). The benefits of merging leadership research and emotions research. Frontiers in Psychology, 7.

Ibanez-Rafuse, C. (2010). Hiring smiling faces: The moderating role of emotional intelligence when performing emotional labor among a sample of flight attendants. Unpublished $P h D$, Capella University, $M N$.

Jackson, S. E., Turner, J. A., \& Brief, A. P. (1987). Correlates of burnout among public service lawyers. Journal of Organizational Behavior, 8(4), 339-349.

Johnson, H.-A. M., \& Spector, P. E. (2007). Service with a smile: do emotional intelligence, gender, and autonomy moderate the emotional labor process? Journal of occupational health psychology, 12(4), 319.

Kalat, J., \& Shiota, M. (2007). Emotion. Belmont. CA: Thompson Wadsworth.

Kammeyer-Mueller, J. D., Rubenstein, A. L., Long, D. M., Odio, M. A., Buckman, B. R., Zhang, Y., \& Halvorsen-Ganepola, M. D. (2013). A Meta-Analytic Structural Model of Dispositonal Affectivity and Emotional Labor. Personnel Psychology, 66(1), 4790.

Khan, N. Z. A., Imran, A., \& Nisar, Q. A. (2016). Emotional Exhaustion as Stressor agent for Job Stress in Call Centers: Empirical evidence from perspective of Job Satisfaction and Turnover Intention as Work Outcomes. European Online Journal of Natural and Social Sciences, 5(4), 908.

Kruml, S. M., \& Geddes, D. (2000). Exploring the dimensions of emotional labor the heart of Hochschild's work. Management communication quarterly, 14(1), 8-49.

Kunnanatt, J. T. (2004). Emotional intelligence: The new science of interpersonal effectiveness. Human Resource Development Quarterly, 15(4), 489-495.

Lambert, E. (2003). The impact of organizational justice on correctional staff. Journal of criminal justice, 31(2), 155-168.

Lee, Y. H., \& Chelladurai, P. (2016). Affectivity, Emotional Labor, Emotional Exhaustion, and Emotional Intelligence in Coaching. Journal of Applied Sport Psychology, 28(2), $170-184$. 
Li, M., \& Liang, L. (2016). Emotional Labor between Supervisors and Subordinates: Literature Review and Future Research. Open Journal of Business and Management, 4(01), 130.

Martínez-Íñigo, D., \& Totterdell, P. (2016). The mediating role of distributive justice perceptions in the relationship between emotion regulation and emotional exhaustion in healthcare workers. Work \& Stress, 30(1), 26-45.

Martínez-Iñigo, D., Totterdell, P., Alcover, C. M., \& Holman, D. (2007). Emotional labour and emotional exhaustion: Interpersonal and intrapersonal mechanisms. Work \& Stress, 21(1), 30-47.

Maslach, C. (1982). Burnout: The cost oí caring: Englewood Cliffs, NJ: Prentice Hall.

Maslach, C., \& Jackson, S. E. (1981). The measurement of experienced burnout. Journal of Organizational Behavior, 2(2), 99-113.

Maslach, C., Schaufeli, W. B., \& Leiter, M. P. (2001). Job burnout. Annual review of psychology, 52(1), 397-422.

Mathieu, J. E., \& Zajac, D. M. (1990). A review and meta-analysis of the antecedents, correlates, and consequences of organizational commitment. Psychological bulletin, 108(2), 171.

McEnrue, M. P., \& Groves, K. (2006). Choosing among tests of emotional intelligence: what is the evidence? Human Resource Development Quarterly, 17(1), 9-42.

Meyer, J. P., Stanley, D. J., Herscovitch, L., \& Topolnytsky, L. (2002). Affective, continuance, and normative commitment to the organization: A meta-analysis of antecedents, correlates, and consequences. Journal of vocational behavior, 61(1), 2052.

Miao, C., Humphrey, R. H., \& Qian, S. (2016). Leader emotional intelligence and subordinate job satisfaction: a meta-analysis of main, mediator, and moderator effects. Personality and Individual Differences, 102, 13-24.

Montgomery, A. J., Panagopolou, E., de Wildt, M., \& Meenks, E. (2006). Work-family interference, emotional labor and burnout. Journal of managerial psychology, 21(1), 36-51.

Mowday, R. T., Steers, R. M., \& Porter, L. W. (1979). The measurement of organizational commitment. Journal of vocational behavior, 14(2), 224-247.

Näring, G., Briët, M., \& Brouwers, A. (2006). Beyond demand-control: Emotional labour and symptoms of burnout in teachers. Work \& Stress, 20(4), 303-315.

Newman, A., Thanacoody, R., \& Hui, W. (2011). The impact of employee perceptions of training on organizational commitment and turnover intentions: a study of multinationals in the Chinese service sector. The International Journal of Human Resource Management, 22(8), 1765-1787.

Nisar, Q. A., Imran, A., Othman, N. B., Kamil, B. A. B. M., \& Marchalina, L. (2017). Do leaders' emotional labor strategies influence the leaders' emotional exhaustion? Moderating role of emotional intelligence: Longitudinal study on NGOs. Advanced Science Letters, 23(9), 8131-8137. 
Pakistan Journal of Humanities and Social Sciences, 6(1), 2018

O'Reilly, C. A., \& Chatman, J. (1986). Organizational commitment and psychological attachment: The effects of compliance, identification, and internalization on prosocial behavior. Journal of Applied Psychology, 71(3), 492.

Ottenbacher, M. C., \& Harrington, R. J. (2010). Strategies for achieving success for innovative versus incremental new services. Journal of Services Marketing, 24(1), 315.

Philipp, A., \& Schüpbach, H. (2010). Longitudinal effects of emotional labour on emotional exhaustion and dedication of teachers. Journal of occupational health psychology, 15(4), 494.

Porter, L. W., Steers, R. M., Mowday, R. T., \& Boulian, P. V. (1974). Organizational commitment, job satisfaction, and turnover among psychiatric technicians. Journal of Applied Psychology, 59(5), 603.

Pugh, S. D. (2001). Service with a smile: Emotional contagion in the service encounter. Academy of management Journal, 44(5), 1018-1027.

Raman, P., Sambasivan, M., \& Kumar, N. (2016). Counterproductive work behavior among frontline government employees: Role of personality, emotional intelligence, affectivity, emotional labor, and emotional exhaustion. Revista de Psicología del Trabajo y de las Organizaciones, 32(1), 25-37.

Rathi, N., Bhatnagar, D., \& Mishra, S. K. (2013). Effect of emotional labor on emotional exhaustion and work attitudes among hospitality employees in India. Journal of Human Resources in Hospitality \& Tourism, 12(3), 273-290.

Rubin, R. S., Tardino, V. M. S., Daus, C. S., \& Munz, D. C. (2005). A reconceptualization of the emotional labor construct: On the development of an integrated theory of perceived emotional dissonance and emotional labor. Paper presented at the Annual Conference of the Society for Industrial and Organizational Psychology, 17th, Toronto, ON, Canada; A version of this chapter was presented at the aforementioned conference.

Salancik, G. (1977). Commitment and the control of organizational behaviour and belief In BM Staw \& GR Salancik (Eds), New directions in organizational behaviour. Chicago: St. St. Clair Pres., Chicago.

Saxton, M. J., Phillips, J. S., \& Blakeney, R. N. (1991). Antecedents and consequences of emotional exhaustion in the airline reservations service sector. Human relations, 44(6), 583-595.

Seery, B. L., \& Corrigall, E. A. (2009). Emotional labor: Links to work attitudes and emotional exhaustion. Journal of managerial psychology, 24(8), 797-813.

Shirom, A. (2005). Reflections on the study of burnout The views expressed in Work \& Stress commentaries are those of the author (s), and do not necessarily represent those of any other person or organization, or of the journal. Work \& Stress, 19(3), 263-270.

Sohn, H.-K., Lee, T. J., \& Yoon, Y.-S. (2016). Emotional Labor and Burnout: Comparison Between the Countries of Japan and Korea. Journal of Travel \& Tourism Marketing, 33(5), 597-612.

Steers, R. M. (1977). Antecedents and outcomes of organizational commitment. Administrative science quarterly, 46-56. 
Strongman, K. T. (2003). The psychology of emotion from everyday life to theory: John Wiley and Sons.

Tang, X. L., Gu, Y. K., \& Cui, L. (2017). Influence of leader and employee emotional labor on service performance: A hierarchical linear modeling approach. Social Behavior and Personality, 45(8), 1233-1244.

Tews, M. J., \& Glomb, T. M. (2003). Emotional labor and the five factor model of personality. Paper presented at the annual meeting of the Society for Industrial and Organizational Psychology, Orlando, FL.

Torland, M. (2013). Emotional labour and the job satisfaction of adventure tour leaders in Australia.

Totterdell, P., \& Holman, D. (2003). Emotion regulation in customer service roles: testing a model of emotional labor. Journal of occupational health psychology, 8(1), 55.

Tsai, W.-C. (2001). Determinants and consequences of employee displayed positive emotions. Journal of management, 27(4), 497-512.

Tsai, W.-C., \& Huang, Y.-M. (2002). Mechanisms linking employee affective delivery and customer behavioral intentions. Journal of Applied Psychology, 87(5), 1001.

Volker, R., Bernhard, B., Anna, K., Fabrizio, S., Robin, R., Jessica, P., . . Franz, H. (2010). Burnout, coping and job satisfaction in service staff treating opioid addicts-from Athens to Zurich. Stress and Health, 26(2), 149-159.

Wang. (2011). What role does leaders' emotional labor play in effective leadership? An empirical examination.

Wang, G., Seibert, S. E., \& Boles, T. L. (2011). Chapter 1 Synthesizing What We Know and Looking Ahead: A Meta-Analytical Review of 30 Years of Emotional Labor Research. What Have We Learned, 7, 15-43.

Wilding, M., Chae, K., \& Jang, J. (2015). Emotional labor in Korean local government: Testing the consequences of situational factors and emotional dissonance. Public Performance \& Management Review, 38(2), 316-336.

Williams, E. S., \& Skinner, A. C. (2003). Outcomes of physician job satisfaction: a narrative review, implications, and directions for future research. Health care management review, 28(2), 119-139.

Wright, T. A., \& Cropanzano, R. (1998). Emotional exhaustion as a predictor of job performance and voluntary turnover. Journal of Applied Psychology, 83(3), 486.

Yang, F.-H., \& Chang, C.-C. (2008). Emotional labour, job satisfaction and organizational commitment amongst clinical nurses: A questionnaire survey. International Journal of Nursing Studies, 45(6), 879-887.

Zammuner, V. L., \& Galli, C. (2005). The relationship with patients: Emotional labor and its correlates in hospital employees. Emotions in organizational behavior, 251-285. 